\title{
Antagonistic effect of volatile and non-volatile compounds from Streptomyces strains on cultures of several phytopathogenic fungi
}

\author{
Daniel Alonso Pérez-Corral' ${ }^{1}$, José de Jesús Ornelas-Paz' ${ }^{1}$, Guadalupe Isela Olivas-Orozco ${ }^{1}$, \\ Carlos Horacio Acosta-Muñiz ${ }^{1}$, Miguel Ángel Salas-Marina ${ }^{2}$, María Fernanda Ruiz-Cisneros', \\ Francisco Javier Molina-Corral' ${ }^{1}$, Sylvia Patricia Fernández-Pavía ${ }^{3}$, Claudio Rios-Velasco ${ }^{1 *}$
}

${ }^{1}$ Centro de Investigación en Alimentación y Desarrollo A.C., Unidad Cuauhtémoc, Cd. Cuauhtémoc, Chihuahua, México, ${ }^{2}$ Universidad de Ciencias y Artes de Chiapas, División de Ingeniería, Villa Corzo, Chiapas, México, ${ }^{3}$ Universidad Michoacana de San Nicolás de Hidalgo, Morelia, Michoacán, México

\section{A B S T R A C T}

\begin{abstract}
Fungi and oomycetes are important plant pathogens that constantly attacked plants, thus compromising the production of foods worldwide. Streptomyces strains might be useful to control fungal pathogens by different mechanism. The in vitro antagonistic activity of non-volatile and volatile metabolites from four Streptomyces strains was evaluated over cultures of phytopathogenic fungi and oomycetes. The nonvolatile compounds from Streptomyces strains significantly reduced (44.2 to $92.1 \%$ ) the growth of aerial mycelium of pathogens. The volatile compounds (VOCs) from Streptomyces strains reduced both aerial mycelium (22.5 to $96.7 \%$ ) and mycelium growing inside of culture medium $(0.0-9.4 \%)$. The pathogens maintained their capacity to grow normally in fresh culture medium without antagonists after confrontations with antagonist VOCs. The analysis of VOCs by gas chromatography coupled to mass spectrometry revealed different kinds of VOCs included alcohols, aldehydes, ketones, esters, terpenes, terpenoids, thioethers, among others. The most abundant VOCs were trans-1,10-dimethyl-trans-9-decalol (geosmin), 2-methylisoborneol, 2-methyl-2-bornene, 1,4-dimethyladamantane, and 4-penten-1ol, trifluoroacetate. The antipathogenic activity of nine pure VOCs that had been identified in cultures of the Streptomyces strains alone was evaluated in vitro against phytopathogenic fungi and oomycetes. Trans-2-hexenal was the most effective of these VOCs, inhibiting completely the growth of tested phytopathogens. The volatile and non-volatile compounds from Streptomyces strains effectively reduced the in vitro growth of phytopathogens and they might be used as biological control. Further studies are required to demonstrate this activity on open field conditions.
\end{abstract}

Keywords: Antibiosis; Beneficial microorganisms; Biological control; Fungal phytopathogens; Oomycetes

\section{INTRODUCTION}

Plants are constantly attacked by a wide diversity of phytopathogenic microorganisms, causing important crop losses in preharvest $(\geq 20 \%)$ and postharvest $(\geq 10 \%)$ (Bebber and Gurr, 2015). The annual cost of these losses worldwide has been estimated to be of billions of dollars (Sikes et al., 2018). Fungi and oomycetes are important plant pathogens, compromising significantly the production of foods worldwide (Möller and Stukenbrock, 2017). These complications are not new, and phytopathogens have been a widespread problem for a long time, causing negative impacts on availability of plant foods (Fisher et al., 2012). The control of these pathogens is a priority in agriculture and has mainly been based on chemical fungicides, however, the negative impacts of these compounds on the environment, humans, agriculture, and ecology have forced to search for biological control agents, which do not exert the negative effects regarded to chemicals (Marian and Shimizu, 2019; Pliego et al., 2011). Actinomycetales is family of filamentous bacteria (Grampositive) widely known for the its antimicrobial activity (Sharma et al., 2014). The Streptomyces genus belongs to this family, and is widely distributed in nature, especially in soil, and produces a large number of secondary metabolites with antimicrobial activity widely used in agriculture and

\footnotetext{
*Corresponding author:

Claudio Rios-Velasco, Centro de Investigación en Alimentación y Desarrollo A.C., Unidad Cuauhtémoc. Av. Río Conchos, S/N, Parque Industrial, C.P. 31570. Cd. Cuauhtémoc, Chihuahua, México. Phone: (+52) 6255812920. Fax: (+52) 6255812921.

E-mail: claudio.rios@ciad.mx
}

Received: 14 September 2020;

Accepted: 23 November 2020 
industry (Dhanasekaran et al., 2009; Sidda and Corre, 2012; Todosiichuk et al., 2015). This antibiosis have been attributed to non-volatile and volatile compounds (VOCs), although the volatile antibiotics have receive little attention (Scholler et al., 2002). Several non-volatile antimicrobial compounds from Streptomyces against phytopathogenic fungi have been identified, including: valinomycin (Park et al., 2008), reveromycins A and B (Lyu et al., 2017), among others. Streptomyces strains also produce many types of VOCs, including alkanes, alkenes, aromatic hydrocarbons, alcohols, sulfides, ketones, esters, terpenes, among others (Boukaew et al., 2013; Wan et al., 2008). These VOCs are important for the interaction between microorganisms and suppression of pathogens (Guevara-Avendaño et al., 2019). Several phytopathogens such as Penicillium italicum, Botrytis cinerea, Rhizoctonia solani, Fusarium moniliforme, Fusarium oxysporum and Sclerotinia sclerotiorum have successfully been suppressed by VOCs from Streptomyces strains (Boukaew et al., 2013; Li et al., 2010, 2012; Wang et al., 2013; Wu et al., 2015). Recently, Yang et al. (2019) demonstrated that the VOCs from S. alboflavus TD-1 reduced the growth and production of aflatoxins of Aspergillus flavus. Additionally, the Streptomyces genus produces plant-growth promoting compounds, including indole-3-acetic acid (auxin), griseobactin (siderophore), and gibberellic acid (de Jesus Sousa and Olivares, 2016; Dias et al., 2017). Streptomyces strains might be useful for controlling pathogens of crops and increase the productivity of plants (Boukaew et al., 2013). Thus, the aims of the study were as follows: (i) to evaluate the in vitro antagonistic activity of four Streptomyces strains against selected phytopathogenic fungi and oomycetes by non-volatile and volatile metabolites, (ii) to identify the volatile compounds emitted by Streptomyces strains which may be involved in mycelial growth suppression and (iii) to evaluate the efficacy of individual volatile compounds on the suppression of phytopathogenic fungi.

\section{MATERIALS AND METHODS}

\section{Reagents and microorganisms}

All reagents (analytical grade) and standards of VOCs were purchased from Sigma Aldrich Corp. (St. Louis, MO, USA). Four Streptomyces strains (S. cangkringensis CIAD-CA07, S. misionensis CIAD-CA27, S. kanamyceticus CIAD-CA45, and $S$. kanamyceticus CIAD-CA48) used in the study were isolated from maize (corn, Zea mays L.), bean (Phaseolus vulgaris L.), and apple (Malus domestica Borkh.) crops, respectively, in Chihuahua, Mexico and were preserved on International Streptomyces Project Medium Number 4 agar (ISP4) at $4{ }^{\circ} \mathrm{C}$. The fungal pathogens Fusarium solani (FSO) and Alternaria alternata (AAL) obtained from the ceparium of the Centro de Investigación en Alimentación y Desarrollo A.C. (Campus Cuauhtémoc, Chihuahua) were isolated from tomato (Solanum lycopersicon L.) and apple (Malus domestica Borkh.) crops in Chihuahua, Mexico. These fungal isolates were morphologically identified based on cultural and microscopic characteristics as described by Watanabe (2010), and then, corroborated by Dra. Sylvia Patricia Fernández-Pavía (Universidad Michoacana de San Nicolás de Hidalgo, México-UMSNH). Oomycetes Phytophthora capsici (PHC) strain CPV-283 (AR26) isolated from pepper (Capsicum annumm L.) in Yurécuaro, Michoacán, Mexico; Pythium aphanidermatum (PYA) isolated from papaya (Carioca papaya L.) from Pescadero, Baja California Sur, Mexico; and Phytopythium vexans (PPV) from avocado (Persea americana Mill.) in Xalisco, Nayarit, México were provided by Dra. Fernández-Pavía obtained from a collection belonging to the Instituto de Investigaciones Agropecuarias y Forestales of the UMSNH. These isolates were selected based on their pathogenic capacity documented in previous studies (Castro-Rocha et al., 2016; Rodriguez-Alvarado et al., 2001). The fungal isolates F. solani and $A$. alternata were maintained on Potato Dextrose Agar (PDA) at $4{ }^{\circ} \mathrm{C}$. The oomycetes $P$. capsici, $P$. aphanidermatum, and $P$. vexans were maintained on Corn Meal Agar (CM). The microorganisms were sub-cultured on fresh media at $28 \pm 1{ }^{\circ} \mathrm{C}$ for $5-7 \mathrm{~d}$ previous to be used.

\section{Molecular identification of Streptomyces isolates}

The identification of Streptomyces strains was based on the analysis of the partial gene sequence encoding $16 \mathrm{~S}$ rRNA from genomic DNA extracted according to RuizCisneros et al. (2017). To amplify the region of $16 \mathrm{~S}$ rRNA gene, fragment was prepared by PCR amplification using the high guanine-cytosine bacteria oligonucleotides F243 (5'-GGATGAGCCCGCGGCCTA-3') and R1378 (5-'CGGTGTGTACAAGGCCCGGGAACG-3') (Duthoit et al., 2003). These PCR products were examined by electrophoresis on a 1\% agarose gel and then, were sequenced at Macrogen Company (Rockville, MD, USA). The obtained sequences were deposited to NCBI database (GenBank). Further phylogenetic analysis by maximum likelihood method was performed using the MEGA X software (Kumar et al., 2018), and Tamura 3-parameter model with values based on 1,000 bootstrapping replicates.

\section{Antagonistic activity of non-volatile compounds from Streptomyces}

The antifungal activity of Streptomyces strains was assessed against five pathogens by dual culture method in Petri dishes of $90 \mathrm{~mm}$ of diameter containing Czapek Dox Agar (CDA) (Fig. 1). Circle explants (7 mm of diameter) of each isolate were placed on four equidistant points of a Petri dish and incubated at $28 \pm 1{ }^{\circ} \mathrm{C}$ for $10 \mathrm{~d}$, according to DávilaMedina et al. (2013). The radial growth of the pathogens was measured every $24 \mathrm{~h}$ until fungi and oomycetes filled 
the control Petri dishes. The inhibition of the radial growth (IRG) was determined using the formula reported by Evangelista-Martínez et al. (2020). The bioassays included nine replicates for each confrontation.

\section{Antifungal activity of volatiles from Streptomyces}

The Streptomyces strains were grown on cooked-sterile wheat grains incubated for $10 \mathrm{~d}$ described by Wan et al. (2008) and Boukaew et al. (2013) with modifications. Then, $15 \mathrm{~g}$ of inoculated wheat were placed on Petri dishes $(90 \mathrm{~mm}$ diameter). On the other hand, a circle explant ( $7 \mathrm{~mm}$ of diameter) containing mycelium and spores of the pathogen was placed at the center of another Petri dish containing CDA medium. Both Petri dishes were opened and placed face to face according to Yang et al. (2019). Control Petri dishes only contained sterile wheat grains (Fig. 1). The dishes were incubated at $28 \pm 1{ }^{\circ} \mathrm{C}$ and the colony diameter of each dish was measured systematically every $24 \mathrm{~h}$. The IRG was calculated as indicated above. A poor aerial mycelium growth was observed, compared to mycelium inside of the medium in this assay. In both, the mycelial growth was measured using a digital caliper (KNOVA, Mexico) under a stereomicroscope (Leica G26). Thus, explants of these mycelia were placed in Petri dishes with PDA in absence of Streptomyces and incubated at the same conditions indicated above to determine if they were able to recover their normal growth rate.

\section{Analysis of volatile compounds by GC-MS}

The analysis of VOCs from Streptomyces was carried out according to Wan et al. (2008), with modifications. After $10 \mathrm{~d}$ of incubation, $100 \mathrm{~mL}$ of saturated sodium chloride sterile solution were added to the $250 \mathrm{~mL}$ bottles containing wheat grains (30 g) inoculated with Streptomyces.

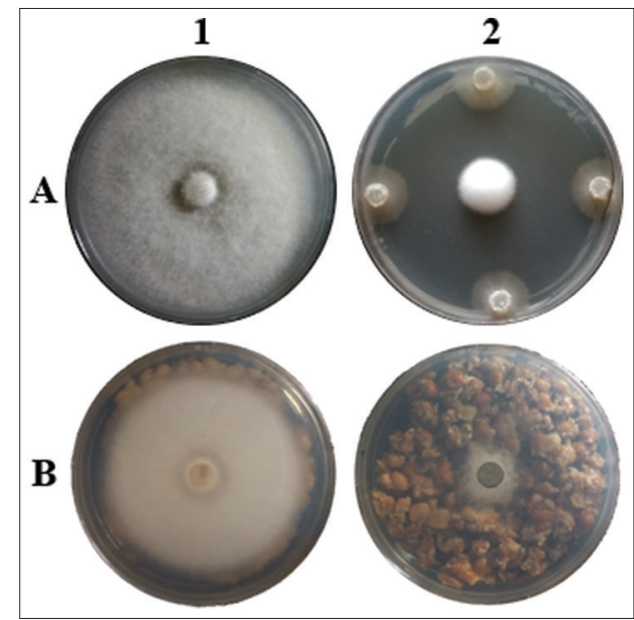

Fig 1. In vitro inhibition of mycelial growth of plant pathogenic fungi by Streptomyces strains. (A1 and B1) Mycelial growth of fungal control on CDA medium and wheat grains, respectively. (A2 and B2) Antifungal activity of non-volatile compounds by dual culture method and volatile compounds using two inverse face-to-face Petri Dishes.
Control treatments contained cooked-sterile wheat without Streptomyces strains. The mixtures were stirred at $400 \mathrm{rpm}$ at $60^{\circ} \mathrm{C}$ for $1 \mathrm{~h}$. The VOCs were collected during $40 \mathrm{~min}$ by a DVB/CAR/PDMS fiber $(50 / 30 \mu \mathrm{m}$ film thickness) and analyzed by gas chromatography coupled to mass spectrometry (VARIAN SATURN 2100D, CA, USA). The samples were injected in the splitless mode. The VOCs were continuously desorbed at $240{ }^{\circ} \mathrm{C}$ and separated in a Hewlett Packard HP-5 column $(30 \mathrm{~m} \times 0.25 \mathrm{~mm}, 0.25 \mu \mathrm{m})$. The initial temperature of the oven was $40^{\circ} \mathrm{C}$, which was kept constant for $2 \mathrm{~min}$. Then, the oven temperature increased to $150{ }^{\circ} \mathrm{C}$ at a rate of $2{ }^{\circ} \mathrm{C} / \mathrm{min}$, then at $280{ }^{\circ} \mathrm{C}$ at a rate of $100{ }^{\circ} \mathrm{C} / \mathrm{min}$ remaining at such temperature for $2 \mathrm{~min}$. Helium gas was used as carrier at a flow rate of $1 \mathrm{~mL} / \mathrm{min}$. The mass spectra were in the range of $\mathrm{m} / \mathrm{z}$ of 35 to 500 . The identification was performed by comparing the MS spectra with those of the National Institute of Standards and Technology (NIST) database. These experiments were performed in triplicate.

\section{Antagonistic activity of pure VOCs against phytopathogens}

The antifungal activity of pure VOCs: 2-pentanone, 2-(methylthio) ethanol, trans-2-hexenal, 2,5- dimethylfuran, $\alpha$-pinene, 2-methyl-3-pentanone, 3-methyl-2-butanol, geosmin +2 -methylisoborneol, valencene and dimethyl disulfide (positive control) were individually assessed in vitro against pathogens according to the method of Yang et al. (2019). The concentration of the volatiles was adjusted to $100 \mu \mathrm{l} \cdot \mathrm{L}^{-1}$. The IRG was calculated as indicated above. Filter papers without VOCs were used as control treatments.

\section{Data analysis}

The experiment was performed under a completely randomized design with three replicates. The data were analyzed by an analysis of variance (ANOVA) and an analysis of means by the Tukey test $(p=0.05)$. The IRG values were studied by principal component analysis.

\section{RESULTS}

\section{Molecular identification of Streptomyces isolates}

The analysis of the partial 16S rRNA gene sequence revealed high similarities of Streptomyces isolates with identities $>99 \%$ compared to those deposited in the NCBI/BLAST database. Based on molecular characters and phylogenetic analysis of 16S rRNA gene Streptomyces strains were identified as $S$. cangkringensis CIAD-CA07, S. misionensis CIADCA27, S. kanamyceticus CIAD-CA45, and S. kanamyceticus CIAD-CA48) (Fig. 2) and DNA sequences were deposited in GenBank under accession numbers MK968576.1, MK968589.1, MK968601.1, and MK968603.1, respectively. 
Antagonistic activity of non-volatile compounds from Streptomyces

The Streptomyces strains significantly reduced the IRG values of tested pathogens, according to the outcome of dual confrontation assays (Fig. 3). This reduction ranged from 44.69 to $78.38 \%$ for $A$. alternata, from 44.24 to $86.50 \%$ for $F$. solani, from 70.76 to $92.10 \%$ for P. capsici, from 52.25 to $79.95 \%$ for $P$. vexans and from 60.67 to $88.51 \%$ for $P$. aphanidermatum. The highest IRG was caused by $S$. kanamyceticus CIAD-CA45 against P. capsici $(92.10 \%)$, while the lowest values (44.69 and $44.24 \%$ ) were caused by $S$. kanamyceticus CIAD-CA48 against $A$. alternata and F. solani, respectively. The principal component analysis (Fig. 4) showed that the strains $S$. cangkringensis CIAD-CA07 and S. misionensis CIAD-CA27 significantly decreased the growth of phytopathogenic fungi (F. solani and $A$. alternata), while the strains $S$. kanamyceticus CIAD-CA45 and S. kanamyceticus CIAD-CA48 mostly reduced the growth of phytopathogenic Oomycetes (P. capsici, $P$. aphanidermatum and P. vexans).

\section{Antifungal activity of volatiles from Streptomyces}

The pathogens exposed to VOCs emitted by Streptomyces strains apparently did not develop aerial mycelium on the culture medium, however, when observing under

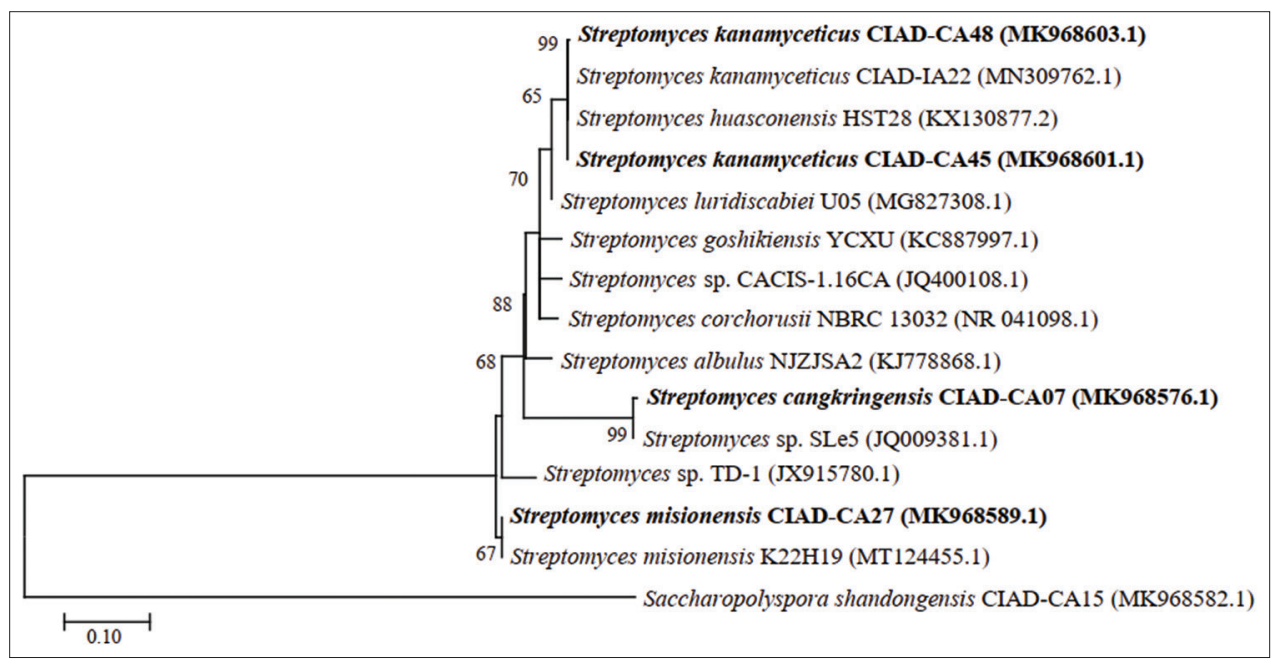

Fig 2. Phylogenetic tree of maximum likelihood and Tamura 3-parameter model based on 16S rRNA gene region sequences showing phylogenetic affinities of Streptomyces isolates belonging to S. kanamyceticus, S. cangkringensis and S. misionensis. Strains in this study are highlighted in bold. Support values exceeding $50 \%$, are indicated at the nodes as percentage values based on 1,000 bootstrap replicates. Scale bar corresponds to 0.10 nucleotide substitutions per site. The tree is rooted with Saccharopolyspora shandongensis CIAD-CA15.

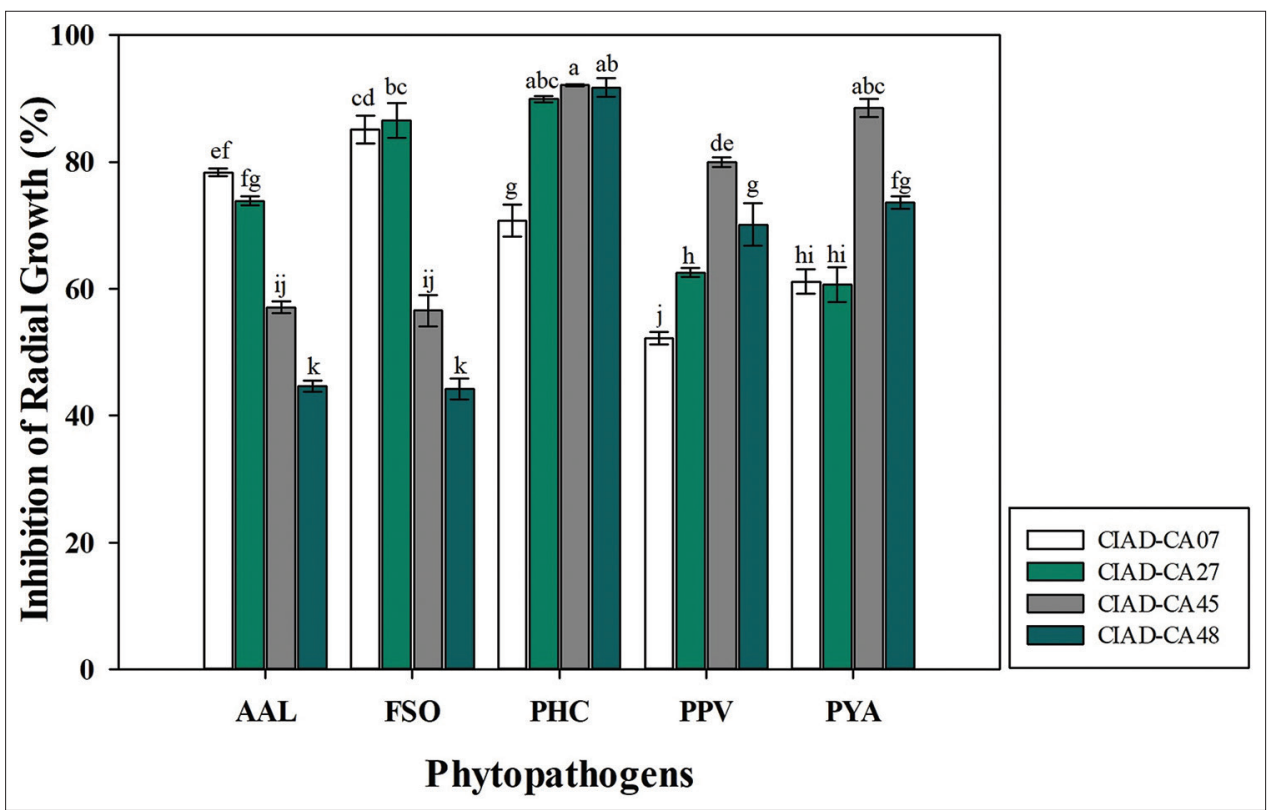

Fig 3. Inhibition of radial growth (IRG) of common phytopathogens by Streptomyces strains by dual confrontation. Phytopathogens: Alternaria alternata (AAL), Fusarium solani (FSO), Phytophthora capsici (PHC), Phytopythium vexans (PPV), and Pythium aphanidermatum (PYA). Mean values connected by same letters are statistically similar. Slim upper bars indicate the standard deviation of means. 
the stereomicroscope a sparse mycelium inside of the culture medium was observed (Fig. 5), therefore, both aerial mycelium and mycelium inside of the medium were measured. The IRG values for aerial mycelium ranged from 81.29 to $96.49 \%$ for $A$. alternata, from 64.74 to $96.74 \%$ for F. solani, from 48.11 to $80.35 \%$ for P. capsici, from 22.58

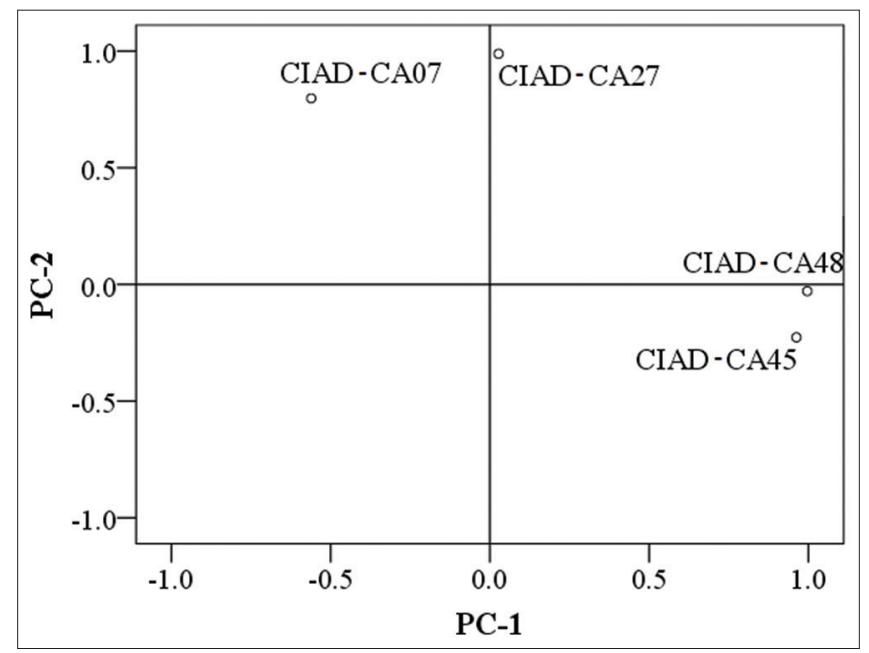

Fig 4. Principal component analysis for inhibition data of Streptomyces strains against common phytopathogens by dual confrontation. Scores (PC-1 and PC-2) for the different values of IRG are showed with the loadings.

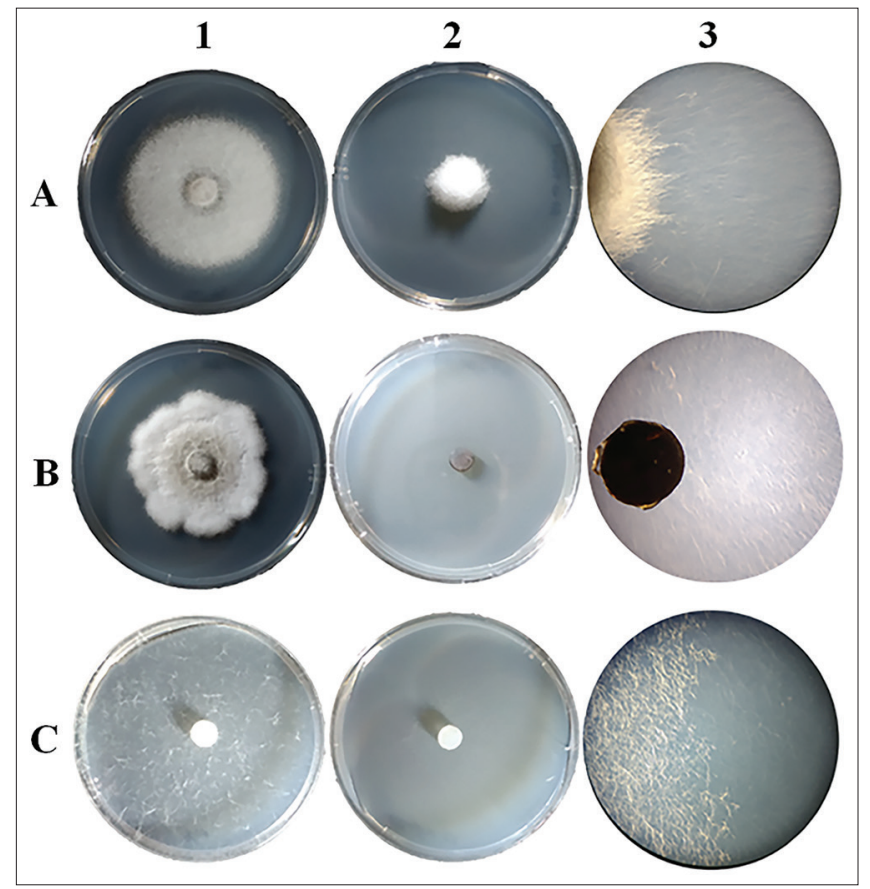

Fig 5. Types of mycelial fungal growth induced by volatile compounds emitted by Streptomyces strains. 1A-1C) Fungal controls (1A: Fusarium solani, 1B: Alternaria alternata, 1C: Pythium aphamidermatum). In vitro confrontations: $2 \mathrm{~A}-2 \mathrm{C}$ ) Showed aerial growth and $3 \mathrm{~A}-3 \mathrm{C}$ ) growth beneath the culture medium on $F$. solani, $A$. alternata and $P$. aphamidermatum in presence of Streptomyces cangkringensis CIAD-CA07, S. misionensis CIAD-CA27 and S. kanamyceticus CIAD-CA45 respectively. to $59.84 \%$ for $P$. vexans, and from 52.87 to $96.26 \%$ for P. aphanidermatum (Fig. 6). The VOCs from Streptomyces strains were less effective to reduce the growth of mycelium inside of the medium, with IRG ranging from 0.00 to $7.51 \%$ for $A$. alternata, from 1.24 to $9.39 \%$ for F. solani, from 0.00 to $4.08 \%$ for P. capsici, from 0.00 to $7.38 \%$ for P. vexans, and from 0.00 to $0.93 \%$ for $P$. aphanidermatum (Fig. 6). All samples of aerial mycelium and mycelium growing inside of the medium recovered their normal growth rate after being placed in fresh PDA without Streptomyces strains.

\section{Analysis of volatile compounds by GC-MS}

The number of VOCs identified in the headspace of bottles containing wheat inoculated with $S$. cangkringensis CIAD-CA07, S. misionensis CIAD-CA27, S. kanamyceticus CIAD-CA45 and S. kanamyceticus CIAD-CA48 was 22, 26,15 , and 10 , respectively (Table 1 ). The volatile profile depended of the strain. These VOCs were alcohols, aldehydes, ketones, esters, terpenes, terpenoids, thioethers, among others. S. cangkringensis CIAD-CA07 mainly produced 2-methylisoborneol and 2-methyl-2-bornene. The most abundant volatile observed in cultures of S. misionensis CIAD-CA27 were trans-1,10-dimethyl-trans9-decalol (geosmin) and 1,4-dimethyladamantane, while S. kanamyceticus CIAD-CA48 mainly produced 4-penten-1ol, trifluoroacetate. The $S$. kanamyceticus strain CIAD-CA45 showed a low production of VOCs (Table 1).

\section{Antagonistic activity of pure VOCs against phytopathogens}

Pure VOCs caused different IRGs (Table 2) and only trans2-hexenal completely inhibited the mycelial growth of all pathogens at a concentration of $100 \mu \mathrm{l} \cdot \mathrm{L}^{-1}$. Dimethyl disulfide (positive control) caused IRGs ranged from 26.29 to $99.93 \%$. The IRGs for the other pure VOCs ranged from 0.9 to $63.4 \%$. Phytophthora capsici was the most susceptible pathogen to tested VOCs.

\section{DISCUSSION}

Phylogenetic analysis of the Streptomyces isolates showed separations within species related and some others selected for their ability to produce antimicrobial metabolites (Fig. 2). These variations might be related to the genetic variability, which cause differences in the morphology, metabolism and antifungal activity (Quecine et al., 2008). In this regard, Al_husnan and Alkahtani (2016) mentioned that although several Streptomyces species are closely related, there are strains among the same species capable of producing different antifungal secondary metabolites.

Tested Streptomyces strains reduced the growth of pathogens when both microorganism types shared the same culture 


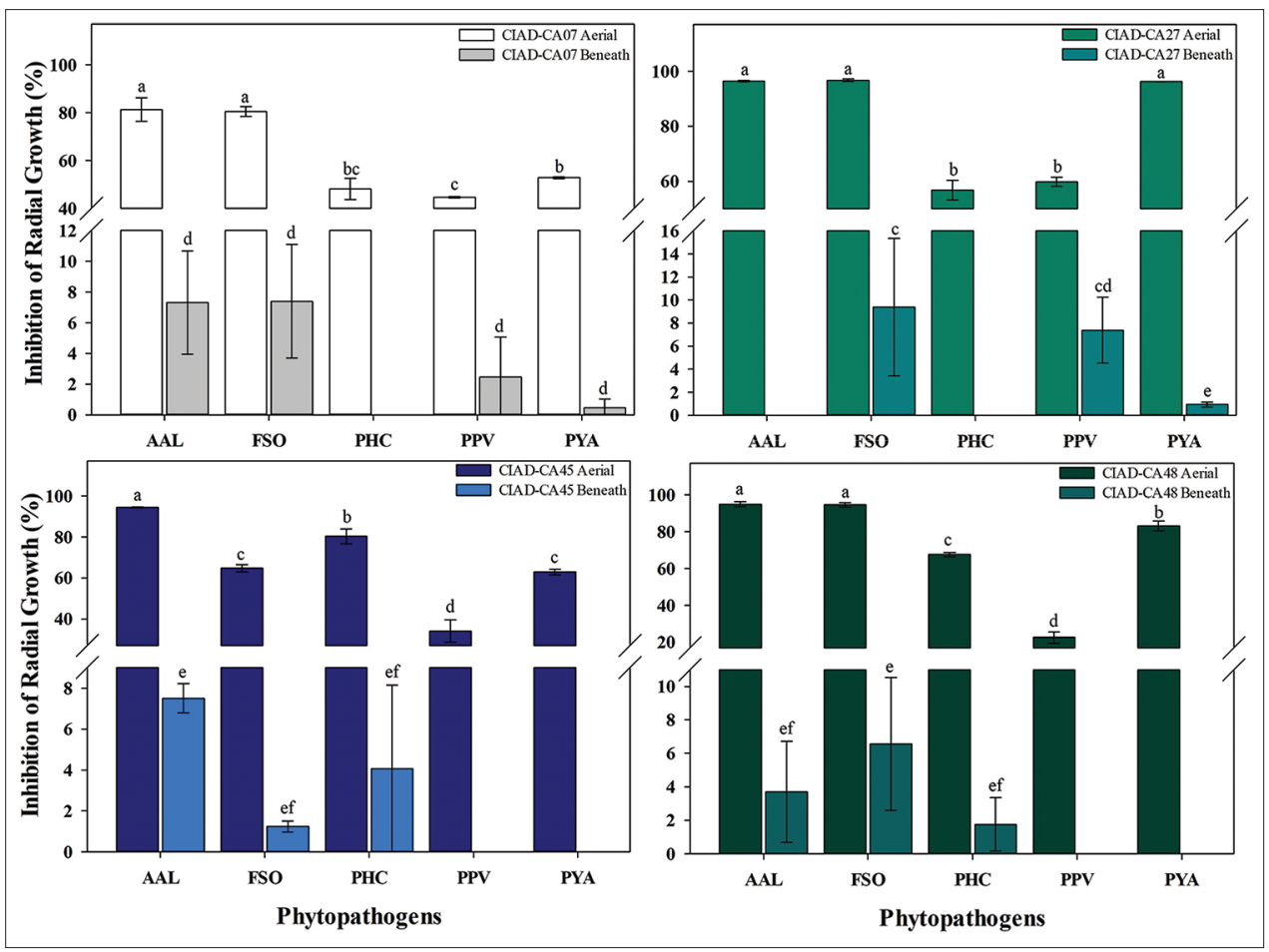

Fig 6. Inhibition of radial growth (IRG) of common phytopathogens by volatile from Streptomyces strains. Aerial mycelium and mycelium inside of the medium. Pathogens: Alternaria alternata (AAL), Fusarium solani (FSO), Phytophthora capsici (PHC), Phytopythium vexans (PPV), and Pythium aphanidermatum (PYA). Mean values connected by same letters are statistically similar. Slim upper bars indicate the standard deviation of means.

Table 1. Volatile compounds produced by Streptomyces strains (S. cangkringensis CIAD-CA07, S. misionensis CIAD-CA27, S. kanamyceticus CIAD-CA45 and S. kanamyceticus CIAD-CA48).

\begin{tabular}{|c|c|c|c|c|c|}
\hline \multirow[t]{2}{*}{ Possible volatile compound } & \multirow[t]{2}{*}{ Retention time (min) } & \multicolumn{4}{|c|}{ Relative peak area (\%) } \\
\hline & & CA07 & CA27 & CA45 & CA48 \\
\hline 2-Butanone, 3-methyl- & 2.295 & -- & -- & 0.283 & -- \\
\hline 2-Butanol, 3-methyl- & 2.515 & -- & -- & 0.425 & -- \\
\hline Hexanoic acid, 2-ethyl-3-hydroxy-, methyl ester & 2.568 & -- & 0.099 & -- & -- \\
\hline 2-Pentanone & 2.591 & 0.086 & -- & 0.316 & -- \\
\hline Furan, 2,5-dimethyl- & 2.826 & -- & 0.143 & -- & -- \\
\hline 4-Penten-1-ol, trifluoroacetate & 3.215 & -- & 0.35 & -- & 7.816 \\
\hline Oxirane, (2-methylbutyl)- & 3.36 & -- & -- & 1.561 & -- \\
\hline Heptane & 3.569 & -- & -- & 3.217 & -- \\
\hline 2-Pentanone, 3-methyl- & 3.595 & -- & -- & -- & 0.791 \\
\hline 3-Pentanol, 2-methyl- & 4.008 & -- & 0.262 & 0.278 & -- \\
\hline Butanoic acid, 2-methyl-, methyl ester & 4.166 & -- & 1.485 & -- & -- \\
\hline 3-Pentanone, 2-methyl- & 4.392 & -- & -- & 0.395 & -- \\
\hline 2-Propenoic acid, 4-methylpentyl ester & 4.46 & 0.092 & -- & -- & -- \\
\hline 2-Oxepanone, 7-methyl & 4.47 & -- & -- & 0.794 & 0.554 \\
\hline Propanoic acid, 2-methoxy-, methyl ester & 4.556 & -- & 0.14 & -- & -- \\
\hline 2-(methylthio) ethanol & 5.971 & -- & -- & -- & 0.623 \\
\hline trans-2-Hexenal & 5.981 & -- & 0.262 & -- & -- \\
\hline 3-Pentanone, 2,2-dimethyl & 5.983 & -- & -- & 0.644 & -- \\
\hline Cyclopentanol, 2-methyl- & 6.084 & -- & 0.435 & -- & -- \\
\hline (S)-3,4-Dimethylpentanol & 7.195 & -- & 0.409 & -- & -- \\
\hline 2,5-Dimethylhex-5-en-3-yn-2-ol & 7.879 & -- & 0.321 & -- & -- \\
\hline Pentanoic acid, 2,4-dimethyl-, methyl ester & 9.492 & -- & 0.719 & -- & -- \\
\hline (1R)-2,6,6-Trimethylbicyclo [3.1.1] hept-2-ene & 9.778 & 0.097 & -- & -- & -- \\
\hline 1,3-Benzenediol, 4-ethyl- & 10.229 & -- & 0.183 & -- & -- \\
\hline 3-Hexen-2-one, 3,4-dimethyl- & 11.43 & -- & -- & 2.535 & -- \\
\hline
\end{tabular}


Table 1. (Continued)

\begin{tabular}{|c|c|c|c|c|c|}
\hline \multirow[t]{2}{*}{ Possible volatile compound } & \multirow[t]{2}{*}{ Retention time (min) } & \multicolumn{4}{|c|}{ Relative peak area (\%) } \\
\hline & & CA07 & CA27 & CA45 & CA48 \\
\hline Bicyclo[3.1.0]Hexane, 4-methylene-1-(1-methylethyl)- & 12.01 & 0.209 & -- & -- & -- \\
\hline Benzene, 1-ethoxy-4-ethyl- & 12.182 & 1.234 & -- & -- & -- \\
\hline 2-Methylenebornane & 12.474 & 1.326 & -- & -- & -- \\
\hline 3-Octene-2,6-dione, 5,5,7-trimethyl-, (E)- & 13.422 & -- & 0.253 & -- & -- \\
\hline 2-Methyl-2-bornene & 14.323 & 5.418 & -- & -- & -- \\
\hline Pentanoic acid, 3-hydroxy-2-methyl-, methyl ester & 14.48 & -- & 0.475 & -- & -- \\
\hline 3-Penten-2-one & 14.608 & -- & 0.421 & -- & -- \\
\hline Hexanoic acid, 2 ethyl-, methyl ester & 16.553 & -- & -- & 0.435 & -- \\
\hline 2-Cyclopenten-1-one, 2-(2-butenyl)-4-hydroxy-3-methyl-, (Z)- & 22.754 & -- & -- & 1.006 & -- \\
\hline Benzenamine, 2,3,4,5,6-pentametyl- & 24.191 & -- & -- & 0.549 & -- \\
\hline 2-Methylisoborneol & 25.185 & 40.465 & -- & -- & -- \\
\hline 1,4-Dimethyladamantane & 27.687 & 1.556 & 12.927 & -- & -- \\
\hline 1H-Idene, 1-ethylideneoctahydro-7a-methyl-, (1Z,3a.alpha.,7a.beta.)- & 29.166 & -- & 1.168 & -- & -- \\
\hline 3,4-Dimethoxytoluene & 29.38 & -- & -- & -- & 0.292 \\
\hline $\begin{array}{l}\text { 1,3a-Ethano-3aH-indene, } \\
\text { 1,2,3,6,7,7a-hexahydro-2,2,4,7a-tetramethyl-, [1R-(1.alpha.,3a. } \\
\text { alpha.,7a.alpha.)]- }\end{array}$ & 33.532 & 0.295 & -- & -- & -- \\
\hline 1-Ethyl-3-(propen-1-yl) adamantane & 34.221 & 0.255 & -- & -- & -- \\
\hline beta.-Neclovene & 35.598 & 2.793 & -- & -- & -- \\
\hline beta.-Guaiene & 36.765 & 0.193 & -- & -- & -- \\
\hline 1R,4R,7R,11R-1,3,4,7-Tetramethyltricyclo[5.3.1.0 (4,11) undec-2ene & 37.476 & 0.156 & -- & -- & -- \\
\hline Tricyclo[3.2.1.02,7]oct-3-ene, 2,3,4,5-tetramethyl- & 38.041 & 0.899 & -- & -- & -- \\
\hline trans-1,10-Dimethyl-trans-9-decalol (geosmin) & 39.13 & 4.001 & 43.328 & -- & -- \\
\hline $\begin{array}{l}\text { (4R,4aR)-4,4a-Dimethyl-6-(prop-1-en-2-yl)-1,2,3,4,4a, } \\
\text { 7-hexahydronaphthalene }\end{array}$ & 39.373 & 0.286 & -- & -- & -- \\
\hline Bicyclo[4.4.0]dec-1-ene, 2-isopropyl-5-methyl-9-methylene- & 39.598 & -- & -- & -- & 1.514 \\
\hline 2-Undecanone, 6,10-dimethyl- & 39.844 & -- & -- & -- & 0.825 \\
\hline $\begin{array}{l}\text { (3S,3aS,6R,8aS)-3,7,7-Trimethyl-8-methyleneoctahydro-1H-3a, } \\
\text { 6-methanoazulene }\end{array}$ & 42.23 & -- & -- & -- & 0.946 \\
\hline (+)-epi-Bicyclosesquiphellandrene & 42.725 & 0.153 & -- & -- & -- \\
\hline $\begin{array}{l}\text { (3R,5aR,9S,9aS)-2,2,5a, } \\
\text { 9.Tetramethyloctahydro-2H-3,9a-methanobenzo[b] oxepine }\end{array}$ & 42.872 & 0.192 & -- & -- & -- \\
\hline Ginsenol & 42.916 & -- & 1.496 & -- & -- \\
\hline gamma.-Muurolene & 43.741 & -- & 0.19 & -- & -- \\
\hline Germacrene D & 43.853 & 1.058 & 1.029 & -- & -- \\
\hline $\begin{array}{l}\text { 2H-3,9a.Methano-1-benzoxepin, octahydro-2,2,5a, } \\
\text { 9-tetramethyl-, [3R-(3.alpha.,5a.alpha.,9.alpha.,9a.alpha.)]- }\end{array}$ & 45.043 & -- & 1.456 & -- & -- \\
\hline $\begin{array}{l}\text { Naphtalene, 1,2,3,4,4a, } \\
\text { 5,6,8a-octahydro-7-methyl-4-methylene-1-(1-methylethyl)-, (1.alpha.,4a. } \\
\text { beta.,8a.alpha.)- }\end{array}$ & 45.897 & -- & 0.507 & -- & -- \\
\hline $\begin{array}{l}\text { Naphtalene, } \\
\text { 1,2,3,5,6,7,8,8a-octahydro-1,8a-dimethyl-7-(1-methylethenyl)-, [1R-(1. } \\
\text { alpha.,7.beta.,8a.alpha.)]- }\end{array}$ & 46.365 & 0.244 & -- & -- & -- \\
\hline $\begin{array}{l}\text { Naphtalene, 1,2,4a, } \\
\text { 5,8,8a-hexahydro-4,7-dimethyl-1-(1-methylethyl)-,[1S-(1.alpha.,4a. } \\
\text { beta.,8a.alpha.)]- }\end{array}$ & 46.561 & -- & 0.756 & -- & -- \\
\hline But-3-enal, 2methyl-4-(2,6,6-trimethyl-1-cyclohexenyl)- & 46.738 & -- & 0.291 & -- & -- \\
\hline Hexanoic acid, 3,5,5-trimethyl-, octyl ester & 50.536 & -- & -- & 1.905 & -- \\
\hline $\begin{array}{l}\text { 2-Naphthalenemethanol, decahydro-. } \\
\text { alpha.,.alpha.,4a-trimethyl-8-methylene-, [2R-(2.alpha.,4a.alpha.,8a. } \\
\text { beta.)]- }\end{array}$ & 52.995 & -- & 0.311 & -- & -- \\
\hline 1,8,11-Heptadecatriene, $(Z, Z)-$ & 54.627 & -- & -- & 1.129 & 4.386 \\
\hline Estra-1,3,5 (10)-trien-17-one, 3,4-bis[(trimethylsilyl) oxy]- & 58.659 & 0.05 & -- & -- & -- \\
\hline
\end{tabular}


Pérez-Corral, et al.

Table 2. Inhibition of radial growth (IRG) of common phytopathogenic fungi and oomycetes by pure volatile compounds

\begin{tabular}{|c|c|c|c|c|c|}
\hline & \multicolumn{2}{|c|}{ Fungi } & \multicolumn{3}{|c|}{ Oomycetes } \\
\hline & $\begin{array}{c}\text { Alternaria } \\
\text { alternata }\end{array}$ & $\begin{array}{c}\text { Fusarium } \\
\text { solani }\end{array}$ & Pytopythium vexans & $\begin{array}{c}\text { Pythium } \\
\text { aphamidermatum }\end{array}$ & $\begin{array}{l}\text { Phytophthora } \\
\text { capsici }\end{array}$ \\
\hline $\begin{array}{l}\text { Dimethyl disulfide (positive } \\
\text { control) }\end{array}$ & $26.3 \pm 0.67 b$ & $41.1 \pm 8.0 \mathrm{~b}$ & $65.7 \pm 1.9 \mathrm{~b}$ & $99.9 \pm 0.1 \mathrm{a}$ & $62.6 \pm 3.3 \mathrm{bc}$ \\
\hline trans-2-Hexenal & $100.0 \pm 0.0 \mathrm{a}$ & $100.0 \pm 0.0 \mathrm{a}$ & $100.0 \pm 0.0 \mathrm{a}$ & $100.0 \pm 0.0 \mathrm{a}$ & $100.0 \pm 0.0 \mathrm{a}$ \\
\hline 2-(Methylthio) ethanol & $12.9 \pm 0.9 \mathrm{~cd}$ & $1.1 \pm 0.5 \mathrm{c}$ & $4.6 \pm 1.3 \mathrm{~g}$ & $0.9 \pm 1.7 \mathrm{e}$ & $45.1 \pm 5.6 \mathrm{e}$ \\
\hline 2-Pentanone & $13.9 \pm 1.7 \mathrm{c}$ & $1.3 \pm 0.9 \mathrm{c}$ & $14.8 \pm 2.5 f$ & $14.2 \pm 4.7 \mathrm{~d}$ & $53.6 \pm 2.7 \mathrm{cde}$ \\
\hline 2,5- Dimethylfuran & $6.4 \pm 2.7 \mathrm{~d}$ & $6.4 \pm 1.1 \mathrm{c}$ & $26.4 \pm 4.3$ de & $56.9 \pm 3.5 b$ & $58.1 \pm 5.5 \mathrm{bcd}$ \\
\hline$\alpha$-Pinene & $9.8 \pm 4.5 \mathrm{~cd}$ & $5.4 \pm 0.7 \mathrm{c}$ & $10.8 \pm 3.6 \mathrm{fg}$ & $28.4 \pm 5.6 \mathrm{c}$ & $60.7 \pm 3.2 \mathrm{bcd}$ \\
\hline 2-Methyl-3-pentanone & $9.3 \pm 2.6 \mathrm{~cd}$ & $1.7 \pm 1.1 \mathrm{c}$ & $19.1 \pm 5.3$ ef & $51.6 \pm 2.4 \mathrm{~b}$ & $63.4 \pm 1.5 \mathrm{~b}$ \\
\hline 3-Methyl-2-butanol & $7.7 \pm 2.4 \mathrm{~cd}$ & $5.83 \pm 3.1 \mathrm{c}$ & $9.8 \pm 5.1 \mathrm{fg}$ & $3.5 \pm 1.9 \mathrm{e}$ & $51.6 \pm 2.3 \mathrm{de}$ \\
\hline Geosmin+2-Methylisoborneol & $7.4 \pm 2.7 \mathrm{~cd}$ & $6.2 \pm 4.4 \mathrm{c}$ & $34.4 \pm 0.8 \mathrm{~cd}$ & $2.5 \pm 0.8 \mathrm{e}$ & $60.3 \pm 1.2 \mathrm{bcd}$ \\
\hline Valencene & $9.5 \pm 3.0 \mathrm{~cd}$ & $4.0 \pm 1.0 \mathrm{c}$ & $40.8 \pm 4.2 c$ & $2.9 \pm 1.6 \mathrm{e}$ & $59.0 \pm 3.6 \mathrm{bcd}$ \\
\hline
\end{tabular}

Mean values with same letters between columns are statistically similar \pm standard error

medium or head space, demonstrating that the effect of Streptomyces on pathogens was mediated by non-volatile and volatile compounds. These types of compounds can exert additive or synergistic effects on antimicrobial activity of microorganisms (Korpi et al., 2009; SánchezOrtiz et al., 2016). However, the antifungal VOCs of the Streptomyces genus have received little attention. In our study, the VOCs profile varied among Streptomyces species and even among strains of the same species. Unexpectedly, some of the characteristic VOCs of the Streptomyces genus (geosmin, 2-methyl-2-bornene, and 2-methylisoborneol) were not produced by all Streptomyces strains. These compounds were produced by the strains $S$. cangkeringensis CIAD-CA07 and S. misionensis CIAD-CA27, but $S$. misionensis CIAD-CA27 produced 10 times more geosmin than S. cangkringensis CIAD-CA07. The strains CIAD-CA45 and CIAD-CA48 of S. kanamyceticus did not produce geosmin. These variations undoubtedly altered the antifungal activity of tested strains. Quecine et al. (2008) observed that the non-volatile compounds mediated antifungal activity of strains of the Streptomyces genus was highly dependent of the strain. Similarly, Guo et al. (2019) observed that the antifungal activity of some Trichoderma species (T. harzianum, T. hamatum, and T. velutinum) varied with the specie due differences in their VOCs profile, attributing these differences to genetic variability among tested species. Similar metabolic differences and activities have already been reported for several species and strains of Streptomyces and other genera (Scholler et al., 2002; WeiWei et al., 2008). In our study, several antifungal VOCs were identified in cultures of Streptomyces strains, including phenylethyl alcohol, (+)-epi-bicyclosesquiphellandrene, germacrene D, and 2-(methylthio) ethanol. Li et al. (2010) observed that the biosynthesis of phenylethyl alcohol in S. globisporus reduced the growing of Penicillium italicum. Wan et al. (2008) observed that phenylethyl alcohol and (+)-epi-bicyclosesquiphellandrene from S.platensis inhibited the growth of the fungi Sclerotinia sclerotium and Botrytis cinerea. Fernando et al. (2005) hypothesized that 2-hexenal was part of the defense mechanism of plants against pathogens. 2-pentanone and germacrene $\mathrm{D}$ from $S$. philanthi RM-1-138 also exert antifungal effects (Boukaew et al., 2013; Rocha et al., 2012). Tested Streptomyces strains did not produce high quantities of sulfur-containing antifungal compounds (i.e. isobutyl isothiocyanate, dimethyl disulfide, and 2-(methylthio) ethanol, among others), which are highly produced by other antagonistic microorganisms (i.e. Pseudomonas stutzeri E25, Stenotrophomonas maltophilia CR71, and T. virens) (Angel et al., 2016; Rojas-Solís et al., 2018). Only the strain $S$. kanamycetius CIAD - CA48 produced 2-(methylthio) ethanol, a sulfur-containing compound probably involved in the antifungal activity of this strain. Li et al. (2015) demonstrated that the chemical nature and abundance of VOCs emitted by microorganisms determine their antifungal activity.

The VOCs emitted by Streptomyces strains reduced the aerial growth of fungi and oomycetes in the range of 22.58 to $96.74 \%$. This effect was probably caused by the diffusion of VOCs from Streptomyces strains into the culture medium and/or aerial mycelium, causing a reduction of aerial growth of pathogens (Wei-Wei et al., 2008). Boukaew et al. (2013) observed IRG values from 17.03 to $100 \%$ for dual confrontation assays between phytopathogenic fungi and 
Streptomyces strains and attributed the inhibitory effect to VOCs of Streptomyces. The growth of aerial mycelium in cultures of some pathogens was more susceptible to VOCs of Streptomyces strains. This was the case of $A$. alternata, revealing the importance of VOCs in controlling plant diseases. Amini et al. (2016) also observed that the VOCs from Streptomyces species caused a higher reduction of $F$. oxysporum f. sp. ciceris. This susceptibility of fungi to volatile or non-volatile compounds depends on the antimicrobial mechanisms exerted by Streptomyces strains as well as to the capacity of pathogens to counteract the attack of antagonistic microorganisms (Duffy et al., 2003). In our study, the development of mycelium inside of the medium was observed in VOCs mediated confrontation assays. This behavior had not been reported previously in in vitro studies with antagonistic strains of Streptomyces. It could be caused by the presence of oxygen in agar pores or to the solubility of growth-promoting volatiles in the culture medium (Wei-Wei et al., 2008). Non-volatile compounds from Streptomyces strains reduced the growth of aerial mycelium of phytopathogens by more than $40 \%$. Similarly, Ruanpanun et al. (2010) observed that the growth of pathogenic fungi was reduced from 21.7 to $87.4 \%$ by some actinomycetes. Evangelista-Martínez et al. (2020) also observed that the growth of phytopathogenic fungi was significantly reduced by some strains of the Streptomyces genus. These mechanisms of pathogen inhibition have been reported for other bacterial genera such as Bacillus and Pseudomonas (Chaurasia et al., 2005; Hernández-León et al., 2015; Raza et al., 2015). In our study, the strains CIAD-CA07 and CIAD-CA27 were highly effective for controlling the fungi $F$. solani and $A$. alternata, while the strains CIAD-CA45 and CIAD-CA48 controlled well the Oomycetes P. capcisi, P. vexans, and P. aphanidermatum (Fig. 3). Considering that the cell wall of the oomycetes and fungi is mainly composed by cellulose and chitin, respectively, it can be hypothesized that the antifungal activity of the strains CIAD-CA07 and CIAD-CA27 was determined by the synthesis of chitinase while the antipathogenic activity of the strains CIAD-CA45 and CIAD-CA48 might be related to the biosynthesis of cellulase and glucanase (Duffy et al., 2003; Latijnhouwers et al., 2003).

The trans-2-hexenal completely inhibited mycelial growth of tested pathogens (IRG $=100 \%$ ) (Table 2). Zhang et al. (2017) exposed cultures of Penicillium cyclopium to this compound and found a minimum inhibitory concentration of $160 \mu \mathrm{l} \cdot \mathrm{L}^{-1}$ and a minimum fungicidal concentration of $320 \mu \mathrm{l} \cdot \mathrm{L}^{-1}$. Our results suggest that both values could be lower for tested pathogens, because any of them recovered their normal growth rate after being sub-cultured in fresh medium in absence of the volatile. The antifungal action of this volatile is attributed to its capability to alter the structure of the cellular membrane and increase the leakage of potassium ions and other cellular components (Zhang et al., 2017). Ma et al. (2019) associated the inhibitory effect of this volatile on Aspergillus flavus with the activation of early apoptosis, mitochondrial dysfunction, disruption of pyruvate metabolism, reduction of acetyl-CoA synthesis, and alterations on ATP synthesis and activity of dehydrogenases in the mitochondrion. Yang et al. (2019) found IRGs of 50\% and $100 \%$ at concentrations of $10 \mu \mathrm{l} \cdot \mathrm{L}^{-1}$ and $100 \mu \mathrm{l} \cdot \mathrm{L}^{-1}$ of dimethyl disulfide, respectively. These values are higher than those found in our study for the same volatile. Rojas-Solís et al. (2018) attributed these variations to the differences in tolerance among strains of plant pathogens to VOCs as well as to differences in defense responses and mechanisms. The VOCs 2-pentanone, 2-(methylthio) ethanol, 2,5dimethylfuran, $\alpha$-pinene, 2-methyl-3-pentanone, 3-methyl2-butanol, geosmin +2 -methylisoborneol, valencene also inhibited effectively the growth of pathogenic oomycetes (IRGs above of 50\%), especially of P. capsici, as compared to the fungi. These VOCs are also emitted by other genera of antagonistic bacteria and fungi and are contained in some essential oils (Rouissi et al., 2013; Wang et al., 2013). Our values of IRGs demonstrated that the mixture of VOCs showed stronger antifungal and antioomycete properties than a single VOC. The evaluation of single VOCs, however allow to demonstrate if it possesses or not these properties.

\section{CONCLUSION}

Tested Streptomyces strains inhibited the growth of phytopathogenic fungi and oomycetes by biosynthesizing non-volatile and volatile compounds. The Streptomyces strains emitted several types of VOCs, including alcohols, aldehydes, ketones, esters, terpenes, terpenoids, and thioethers. The trans-2-hexenal completely inhibited the mycelial growth of tested pathogens. New VOCs with anti-phytopathogenic capabilities need to be identified, estimating their minimum inhibitory and fungicidal concentrations. Further studies are required to assess the antifungal activity of volatile mixtures and to confirm the efficacy of tested Streptomyces strains under open field conditions.

\section{ACKNOWLEDGEMENTS}

The authors thank the Sectorial Research Fund for Education- Consejo Nacional de Ciencia y Tecnología (CONACy') (Basic Science Project 286806) for financial support.

\section{Authors' contributions}

Pérez-Corral and Rios-Velasco conceived the study. PérezCorral conducted the experiments. Data were analyzed by Pérez-Corral, Molina-Corral, Olivas-Orozco, Ornelas-Paz and Ruiz-Cisneros. The manuscript was written by PérezCorral and Rios-Velasco with support from Acosta-Muñiz, 
Salas-Marina and Fernández-Pavía. The manuscript was reviewed by Ornelas-Paz and Ruiz-Cisneros. All authors read and approved the manuscript.

\section{REFERENCES}

Al-Husnan, L. A. and Alkahtani, M. D. 2016. Molecular Identification of Streptomyces producing antibiotics and their antimicrobial activities. Ann. Agric. Sci. 61: 251-255.

Amini, J., Z. Agapoor and M. Ashengroph. 2016. Evaluation of Streptomyces spp. against Fusarium oxysporum f. sp. ciceris for the management of chickpea wilt. J. Plant Prot. Res. 56: 257-264.

Angel, L. P. L., M. T. Yusof, I. S. Ismail, B. T. Y. Ping, I. N. A. Azni, N. H. Kamarudin and S. Sundram. 2016. An in vitro study of the antifungal activity of Trichoderma virens $7 \mathrm{~b}$ and a profile of its non-polar antifungal components released against Ganoderma boninense. J. Microbiol. 54: 732-744.

Bebber, D. P. and S. J. Gurr. 2015. Crop-destroying fungal and oomycete pathogens challenge food security. Fungal Genet. Biol. 74: 62-64.

Boukaew, S., A. Plubrukam and P. Prasertsan. 2013. Effect of volatile substances from Streptomyces philanthi RM-1-138 on growth of Rhizoctonia solani on rice leaf. Biocontrol. 58: 471-482.

Castro-Rocha, A., S. Shrestha, B. Lyon, G. L. Grimaldo-Pantoja, J. P. Flores-Marges, J. Valero-Galván and G. Ávila-Quezada. 2016. An initial assessment of genetic diversity for Phytophthora capsici in northern and central Mexico. Mycol. Prog. 15: 15.

Chaurasia, B., A. Pandey, L. M. S. Palni, P. Trivedi, B. Kumar and N. Colvin. 2005. Diffusible and volatile compounds produced by an antagonistic Bacillus subtilis strain cause structural deformations in pathogenic fungi in vitro. Microbiol. Res. 160: 75-81.

Dávila-Medina, M. D., G. Gallegos-Morales, F. D. Hernández-Castillo, Y. M. Ochoa-Fuente and A. Flores-Olivas. 2013. Actinomicetos antagónicos contra hongos fitopatógenos de importancia agrícola. Rev. Mexicana cienc. agric. 4: 1187-1196.

de Jesus Sousa, J. A. and F. L. Olivares. 2016. Plant growth promotion by streptomycetes: Ecophysiology, mechanisms and applications. Chem. Biol. Technol. Agric. 3: 1-12.

Dhanasekaran, D., N. Thajuddin and A. Panneerselvam. 2009. Distribution and ecobiology of antagonistic streptomyces from agriculture and coastal soil in Tamil Nadu, India. J Cult Collect. 6: $10-20$.

Dias, M. P., M. S. Bastos, V. B. Xavier, E. Cassel, L. V. Astarita and E. R. Santarém. 2017. Plant growth and resistance promoted by Streptomyces spp. in tomato. Plant Physiol. Biochem. 118: 479-493.

Duffy, B., A. Schouten and J. M. Raaijmakers. 2003. Pathogen selfdefense: Mechanisms to counteract microbial antagonism. Annu. Rev. Phytopathol. 41: 501-538.

Duthoit, F., J. J. Godon and M. C. Montel. 2003. Bacterial community dynamics during production of registered designation of origin Salers cheese as evaluated by 16S rRNA gene single-strand conformation polymorphism analysis. Appl. Environ. Microbiol. 69: 3840-3848.

Evangelista-Martínez, Z., E. A. Contreras-Leal, L. F. Corona-Pedraza and E. Gastélum-Martínez. 2020. Biocontrol potential of Streptomyces sp. CACIS-1.5 CA against phytopathogenic fungi causing postharvest fruit diseases. Egypt. J. Biol. Pest. Control. 30: 1-10.

Fernando, W. D., R. Ramarathnam, A. S. Krishnamoorthy and
S C. Savchuk. 2005. Identification and use of potential bacterial organic antifungal volatiles in biocontrol. Soil Biol. Biochem. 37: 955-964.

Fisher, M. C., D. A. Henk, C. J. Briggs, J. S. Brownstein, L. C. Madoff, S. L. McCraw and S. J. Gurr. 2012. Emerging fungal threats to animal, plant and ecosystem health. Nature. 484: 186.

Guevara-Avendaño, E., A. A. Bejarano-Bolívar, A. L. Kiel-Martínez, M. Ramírez-Vázquez, A. Méndez-Bravo, E. A. von Wobeser and F. Reverchon. 2019. Avocado rhizobacteria emit volatile organic compounds with antifungal activity against Fusarium solani, Fusarium sp. associated with Kuroshio shot hole borer, and Colletotrichum gloeosporioides. Microbiol. Res. 219: 74-83.

Guo, Y., A. Ghirardo, B. Weber, J. P. Schnitzler, J. P. Benz and M. Rosenkranz. 2019. Trichoderma species differ in their volatile profiles and in antagonism toward ectomycorrhiza Laccaria bicolor. Front. Microbiol. 10: 891.

Hernández-León, R., D. Rojas-Solís, M. Contreras-Pérez, M. del Carmen Orozco-Mosqueda, L. I. Macías-Rodríguez, H. Reyes-de la Cruz and G. Santoyo. 2015. Characterization of the antifungal and plant growth-promoting effects of diffusible and volatile organic compounds produced by Pseudomonas fluorescens strains. Biol. Control. 81: 83-92.

Korpi, A., J. Järnberg and A. L. Pasanen. 2009. Microbial volatile organic compounds. Crit. Rev. Toxicol. 39: 139-193.

Kumar, S., G. Stecher, M. Li, C. Knyaz and K. Tamura. 2018. MEGA $\mathrm{X}$ : Molecular evolutionary genetics analysis across computing platforms. Mol. Biol. Evol. 35: 1547-1549.

Latijnhouwers, M., P. J. de Wit and F. Govers. 2003. Oomycetes and fungi: Similar weaponry to attack plants. Trends Microbiol. 11: 462-469.

Li, Q., P. Ning, L. Zheng, J. Huang, G. Li and T. Hsiang. 2010. Fumigant activity of volatiles of Streptomyces globisporus JK-1 against Penicillium italicum on Citrus microcarpa. Postharvest Biol. Biotechnol. 58: 157-165.

Li, Q., P. Ning, L. Zheng, J. Huang, G. Li and T. Hsiang. 2012. Effects of volatile substances of Streptomyces globisporus JK-1 on control of Botrytis cinerea on tomato fruit. Biol. Control. 61: 113-120.

Li, X. Y., Z. C. Mao, Y. X. Wu, H. H. Ho and Y. Q. He. 2015. Comprehensive volatile organic compounds profiling of Bacillus species with biocontrol properties by head space solid phase microextraction with gas chromatography-mass spectrometry. Biocontrol. Sci. Technol. 25: 132-143.

Lyu, A., H. Liu, H. Che, L. Yang, J. Zhang, M. Wu and G. Li. 2017. Reveromycins A and B from Streptomyces sp. 3-10: Antifungal activity against plant pathogenic fungi in vitro and in a strawberry food model system. Front. Microbiol. 8: 550.

Ma, W., L. Zhao, W. Zhao and Y. Xie. 2019. (E)-2-Hexenal, as a potential natural antifungal compound, inhibits Aspergillus flavus spore germination by disrupting mitochondrial energy metabolism. J. Agric. Food Chem. 67: 1138-1145.

Marian, M. and M. Shimizu. 2019. Improving performance of microbial biocontrol agents against plant diseases. J. Gen. Plant Pathol. 85: 1-8.

Möller, M. and E. H. Stukenbrock. 2017. Evolution and genome architecture in fungal plant pathogens. Nat. Rev. Microbiol. 15: 756.

Park, C. N., J. M. Lee, D. Lee and B. S. Kim. 2008. Antifungal activity of valinomycin, a peptide antibiotic produced by Streptomyces sp. strain M10 antagonistic to Botrytis cinerea. J. Microbiol. Biotechnol. 18: 880-884

Pliego, C., C. Ramos, A. de Vicente and F. M. Cazorla. 2011. Screening for candidate bacterial biocontrol agents against soilborne fungal plant pathogens. Plant Soil. 340: 505-520. 
Quecine, M., W. Araujo, J. Marcon, C. Gai, J. L. D. Azevedo and A. A. Pizzirani-Kleiner. 2008. Chitinolytic activity of endophytic Streptomyces and potential for biocontrol. Lett. Appl. Microbiol. 47: 486-491.

Raza, W., J. Yuan, N. Ling, Q. Huang and Q. Shen. 2015. Production of volatile organic compounds by an antagonistic strain Paenibacillus polymyxa WR-2 in the presence of root exudates and organic fertilizer and their antifungal activity against Fusarium oxysporum f. sp. niveum. Biol. Control. 80: 89-95.

Rocha, P., J. Rodilla, D. Díez, H. Elder, M. Guala, L. Silva and E. Pombo. 2012. Synergistic antibacterial activity of the essential oil of aguaribay (Schinus molle L.). Molecules. 17: 12023-12036.

Rodriguez-Alvarado, G., S. Fernandez-Pavia, J. Geraldo-Verdugo and L. Landa-Hernandez. 2001. Pythium aphanidermatum causing collar rot on papaya in Baja California Sur, Mexico. Plant Dis. 85: 444-444.

Rojas-Solís, D., E. Zetter-Salmón, M. Contreras-Pérez, M. del Carmen Rocha-Granados, L. Macías-Rodríguez and G. Santoyo. 2018. Pseudomonas stutzeri E25 and Stenotrophomonas maltophilia CR71 endophytes produce antifungal volatile organic compounds and exhibit additive plant growth-promoting effects. Biocatal. Agric. Biotechnol. 13: 46-52.

Rouissi, W., L. Ugolini, C. Martini, L. Lazzeri and M. Mari. 2013. Control of postharvest fungal pathogens by antifungal compounds from Penicillium expansum. J. Food Prot. 76: 1879-1886.

Ruanpanun, P., N. Tangchitsomkid, K. D. Hyde and S. Lumyong. 2010. Actinomycetes and fungi isolated from plant-parasitic nematode infested soils: screening of the effective biocontrol potential, indole-3-acetic acid and siderophore production. World J. Microbiol. Biotechnol. 26: 1569-1578.

Ruiz-Cisneros, M. F., C. Rios-Velasco, D. I. Berlanga-Reyes, J. D. J. Ornelas-Paz, C. H. Acosta-Muñiz, A. Romo-Chacón and J. Ibarra-Rendón. 2017. Incidence and causal agents of root diseases and its antagonists in apple orchards of Chihuahua, México. Rev. Mex. Fitopatol. 35: 1-26.

Sánchez-Ortiz, B., R. Sánchez-Fernández, G. Duarte, P. Lappe Oliveras and M. Macías-Rubalcava. 2016. Antifungal, anti-oomycete and phytotoxic effects of volatile organic compounds from the endophytic fungus Xylaria sp. strain PB $3 \mathrm{f3}$ isolated from Haematoxylon brasiletto. J. Appl. Microbiol. 120: 1313-1325.
Scholler, C. E. G., H. Gurtler, R. Pedersen, S. Molin and K. Wilkins. 2002. Volatile metabolites from actinomycetes. J. Agric. Food Chem. 50: 2615-2621.

Sharma, M., P. Dangi and M. Choudhary. 2014. Actinomycetes: Source, identification, and their applications. Int. J. Curr. Microbiol. Appl. Sci. 3: 801-832.

Sidda, J. D. and C. Corre. 2012. Gamma-butyrolactone and Furan Signaling Systems in Streptomyces. Academic Press, United States of America.

Sikes, B. A., J. L. Bufford, P. E. Hulme, J. A. Cooper, P. R. Johnston and R. P. Duncan. 2018. Import volumes and biosecurity interventions shape the arrival rate of fungal pathogens. PLoS Biol. 16: e2006025.

Todosiichuk, T., L. Zelena and V. Klochko. 2015. Multistage selection of soil actinomycete Streptomyces albus as a producer of antimicrobial substances. Emir J Food Agric. 27: 250-257.

Wan, M., G. Li, J. Zhang, D. Jiang and H. C. Huang. 2008. Effect of volatile substances of Streptomyces platensis F-1 on control of plant fungal diseases. Biol. Control. 46: 552-559.

Wang, Z., C. Wang, F. Li, Z. Li, M. Chen, Y. Wang and H. Zhang. 2013. Fumigant activity of volatiles from Streptomyces alboflavus TD-1 against Fusarium moniliforme Sheldon. J. Microbiol. 51: 477-483.

Watanabe, T. 2010. Pictorial Atlas of Soil and Seed Fungi: Morphologies of Cultured Fungi and Key to Species. CRC Press, Boca Raton, Florida.

Wei-Wei, L., M. Wei, B. Y. Zhu, Y. C. Du and L. Feng. 2008 Antagonistic activities of volatiles from four strains of Bacillus spp. and Paenibacillus spp. against soil-borne plant pathogens. Agric. Sci. China. 7: 1104-1114.

Wu, Y., J. E. W. Yuan, W. Raza, Q. Shen and Q. Huang. 2015. Effects of volatile organic compounds from Streptomyces albulus NJZJSA2 on growth of two fungal pathogens. J. Basic Microbiol. 55: 1104-1117.

Yang, M., L. Lu, J. Pang, Y. Hu, Q. Guo, Z. Li and C. Wang 2019. Biocontrol activity of volatile organic compounds from Streptomyces alboflavus TD-1 against Aspergillus flavus growth and aflatoxin production. J. Microbiol. 57: 396-404.

Zhang, J., H. Tian, H. Sun and X. Wang. 2017. Antifungal activity of trans-2-hexenal against Penicillium cyclopium by a membrane damage mechanism. J. Food Biochem. 41: e12289. 